\title{
Scientific conduct and misconduct: honesty is still the best policy
}

\author{
Neelesh Dahanukar ${ }^{1,2} \&$ Sanjay Molur ${ }^{2,3}$ \\ ${ }^{1}$ Indian Institute of Science Education and Research (IISER), First floor, Central Tower, Sai Trinity Building, Garware Circle, \\ Sutarwadi, Pashan, Pune, Maharashtra 411021, India \\ ${ }^{2}$ Zoo Outreach Organization, ${ }^{3}$ Founder \& Chief Editor, Journal of Threatened Taxa, 96 Kumudham Nagar, Villankurichi Road, \\ Coimbatore, Tamil Nadu 641035, India \\ Email: ${ }^{1}$ n.dahanukar@iiserpune.ac.in, ${ }^{2}$ herpinvert@gmail.com
}

Publication of scientific research is a cooperative system where manuscripts are received by journals in good faith that scientific integrity is maintained by authors while performing research and writing articles. This faith is also bi-directional as authors expect that the editorial and reviewing processes are confidential, that the ideas expressed by authors are not misused and that the judgment is fair. Since the dawn of scientific communications, both publishers and authors have abided by this unwritten agreement to further scientific progress. However, like any other cooperative system, even scientific publication is vulnerable to defection by either parties leading to scientific misconducts, which not only leads to controversies, but also shakes the foundation of this cooperative institution.

Scientific misconduct has become a serious concern in recent years with exposure of several high profile cases (for details see Montgomerie \& Birkhead 2005; Triggle \& Triggle 2007; Errami \& Garner 2008; Redman \& Merz 2008; Rathod 2010). As a result of these exposures and in the interest of maintaining scientific integrity many journals have now formalized their policies against scientific misconduct (for example see Aronson 2007; Mukunda \& Joshi 2008; Handa 2008; Editorial 2011), while European Science Foundation and ALLEA (All European Academies) have published a code of conduct for research integrity (Anonymous 2011). With recent research on the nature of scientific misconduct, its social effects and the journal's stand against the same (Martinson et al. 2005; Errami et al.

Date of publication (online): 26 August 2012

Date of publication (print): 26 August 2012

ISSN 0974-7907 (online) | 0974-7893 (print)

Citation: Dahanukar, N. \& S. Molur (2012). Scientific conduct and misconduct: honesty is still the best policy. Journal of Threatened Taxa 4(9): 2845-2848.

OPEN ACCESS | FREE DOWNLOAD (C) (i) Cு
2008; Fanelli 2009; Long et al. 2009; Resnik et al. 2009) it is now becoming clear that journal policies regarding scientific misconduct, which hitherto were only implied, should be put more explicitly in the form of a formal document.

In a recent issue of the Journal of Threatened Taxa $(J o T T)$ (Vol. 4, No. 7) an article authored by Virendra Mathur, Yuvana Satya Priya, Harendra Kumar, Mukesh Kumar and Vadamalai Elangovan was found to be a case of duplication as a similar article was published by the authors elsewhere. The moment this case was brought to our attention, the article was withdrawn from $J O T T$ online issue and appropriate disciplinary actions were taken. This incident made us realize that a formal statement and description of the protocol for defining JoTT policies against misconduct are essential. This editorial, therefore, tries to explain the concept of scientific misconduct and set the grounds for JoTT policies against scientific misconduct.

\section{Understanding what is scientific misconduct}

Before setting JoTT policies against scientific misconduct, it is essential to define the idea of scientific misconduct more objectively. Building upon the different types of scientific misconducts identified by The European Code of Conduct for Research Integrity (Anonymous 2011) and giving a special recognition to duplicate publishing, we identify four types of scientifically unethical behaviors: (i) fabrication (creating a false data), (ii) falsification (manipulation of data), (iii) plagiarism (copying ideas, statements, results, etc. from other author/s without acknowledging the author/s and/or the source), and (iv) self-plagiarism (multiple identical publications with major overlap in ideas, data, inferences, etc.).

Based on different forms of scientifically unethical behaviors, for all practical purposes, we will follow 
and build up on the definition of scientific misconduct provided by Resnik (2003) who defines scientific misconduct as follows:

(1) Misconduct is a serious and intentional violation of accepted scientific practices, common sense ethical norms, or research regulations in proposing, designing, conducting, reviewing, or reporting research.

(2) Punishable misconduct includes fabrication of data or experiments, falsification of data, plagiarism, or interference with a misconduct investigation or inquiry.

(3) A person who commits a form of punishable misconduct may receive a sanction proportional to the seriousness of the misconduct.

(4) Misconduct does not include honest errors, differences of opinion, or ethically questionable research practices.

\section{JoTT policies against scientific misconduct}

JoTT will not tolerate any form of scientific misconduct and all allegations of such nature will be evaluated objectively. JoTT will also not take the decision hastily and all allegations will be reviewed thoroughly before making the final verdict. In any kind of allegation $J_{O T T}$ will follow the protocol provided in Box 1.

Fabrication (false data) and falsification (manipulation of data) are severe crimes and JoTT's rigorous peer-review and editorial process will detect such a fraud. Even if some erroneous data may escape the reviewing process and get published, we believe that future research will expose such faulty data and under such cases JoTT can request authors of the accused publication to provide raw data used for analysis, and will take appropriate disciplinary actions against the accused publication (Box 1). However, another major concern is plagiarism, which, fortunately, has become relatively easy to detect with the advent of internet and online databases. It is essential that authors understand the concept of plagiarism properly and understand its severity to avoid any allegations based on the same.

Plagiarism is copying of ideas, statements, results, data, figures, etc. from other author(s) without acknowledging the original source, either published or unpublished, which may at times include copyright infringement (Amstrong 1993). Plagiarism is ethically wrong because authors try to take credit of ideas stolen from other sources. Self-plagiarism is a form of plagiarism where authors express same ideas, data, representations, etc. in multiple publications without acknowledging the original publication. While, at a glance, self-plagiarism does not appear as unethical stealing of credits, it is still an inappropriate behavior as it leads to multiple duplicate publications and may also contribute to copyright infringement. Copyright infringement is a severe crime especially if the authors have transferred the copyright of their article to the publisher. This issue does not always arise, especially when the publication is licensed under "Creative Commons Attribution 3.0 Unported License", like

Box 1: JoTT policies against scientific misconduct

Any form of scientific misconduct is unacceptable and JoTT reserves the right to expose such work with appropriate level of penalty suitable for the situation.

A. In the case of suspected scientific misconduct, JoTT will follow the protocol given below:

1. The submitted manuscript will be investigated objectively by the chief editor, associate editors and subject editors of JoTT and JoTT will take appropriate actions suitable for the crime.

2. If scientific misconduct is detected during the reviewing or editing process, JoTT will (i) reject the manuscript, (ii) inform the respective heads of institutions of all the authors, and (iii) inform the funding agency(s) about the misconduct.

3. If in doubt of fabrication or falsification, JoTT can ask for raw data, analysis, photographs, genomic sequences, gel pictures, etc. used by the authors.

B. In case scientific misconduct is reported/detected in a published paper, JoTT will take appropriate actions in the following order:

1. The subject editor and/or reviewers of the paper will be asked to comment on any evidence of scientific misconduct.

2. If the investigation suspects misconduct a response will be asked from the authors along with raw data, analysis, photographs, genomic sequences, gel pictures, etc., if applicable.

3. If the response from authors is satisfactory revealing a mistake or misunderstanding, the matter will be resolved

4. If not, JoTT will withdraw the paper from online version and appropriate announcements will be placed in upcoming issue of JoTT.

5. JOTT will also inform the respective head of the institutions of all the authors and the funding agency(s) about the misconduct. 
in the case of $J_{O T T}$, where authors can reproduce the publication or a part of the publication for non-profit purposes by crediting the original source.

\section{Honorable scientific conduct is a two-way street}

Editorial and reviewing policies of the journal are also as important as the process of research and communication for the advancement of science. Peerreview process is the back bone of editorial and reviewing processes. Despite its long and winding history (Spier 2002), the peer-review process has attracted much debate in the recent past with the exposure of high profile cases of scientific misconduct (Relman 1990; Kassirer \& Campion 1994; Berkenkotter 1995; Benos et al. 2007). On the one hand even though it has been realized that the peer review process has its limitations, on the other it is also agreed that currently there are no effective replacements for the process (Relman 1990; Kassirer \& Campion 1994; Berkenkotter 1995; Benos et al. 2007). Smith's (2006) complete negation of the process and accusations that peer-review process is completely flawed, however, is uncalled for. Peer-reviewing is still one of the most reliable processes as at times it does increase the credibility of papers, provide new ideas for authors, increase the quality of scientific communication and catch faulty data (Berkenkotter 1995; Alberts et al. 2008).

JoTT believes in fair review of articles and each article is sent to at least two reviewers and one subject editor from the field. The process of review and editing by the subject editor is double blind - neither the reviewers nor the subject editors are revealed the identity of authors, and the authors are unaware of the reviewers. While some are skeptical about the efficiency of blinding (van Rooyen et al. 1998), in accordance to the studies supporting the effectiveness of blinding (McNutt et al. 1990; Laband \& Piette 1994) we believe that the review process and editing at $J_{O T T}$ is not biased by the name of the authors and their work place. All manuscripts are checked for their scientific rigor, research integrity and scientific content without bias of any kind.

While it is emphasized that the authors of different types of communications to JoTT must practice ethics in science, JoTT requests the reviewers and subject editors of the manuscript to keep the ideas and data of the authors confidential till it is formally published and that they must not steal author's ideas, plagiarize author's work, or make a decision to reject because of conflict of interest. Authors have a right to make an appeal to the chief editor of JoTT if they have substantial grounds to believe that such malpractice has occurred regarding their manuscript. If such allegations are proved correct they will be treated seriously and appropriate disciplinary actions will be taken against the accused reviewers and subject editors.

\section{What is not scientific misconduct}

At this point it is essential to understand what can be classified under scientific misconduct and what cannot. The fourth component of Resnik's (2003) definition of scientific misconduct, which is also further emphasized in Resnik \& Stewart (2012) actually clarifies this issue. More generally, scientific misconduct does not include honest errors, errors in judgment, difference of opinion, ethically questionable research practices or misconduct unrelated to the publication being criticized. Usually such issues can stir a debate, but through the process of response on the article and reply from the authors such issues can be either resolved or lead to healthy scientific discussions that help in furthering scientific thoughts. We at JoTT have always nurtured such scientific debates as they keep the dynamic process of scientific progress rolling. Even though the response and replies section of JoTT has existed since the beginning a more formal introduction to this section is provided in Box 2. It is also possible that sometimes authors miss out on a key reference or key findings while preparing the manuscript. If these omissions are unintentional, authors are not accused of any scientific misconduct. If such issues are raised after publication authors are encouraged to send an addendum in JoTT.

Box 2: Response and Replies section of JoTT
JoTT provides a forum to express critical comments on
recently published articles, which, after peer review, are
published under the section 'Response and Reply' along with
a reply from the authors of the criticized article. Response to
the published article should challenge the main conclusions,
results or methodology of the article and should not be
concerned with trivial issues which do not contribute to a
healthy scientific discussion. JoTT will not consider responses
written in aggressive, unprofessional and unscientific
language. Neither responses nor replies should be personal
attacks. JoTT will send the response to the concerned authors
and ask them for their clarifications and reply. Reply must be
sent only by the authors of the article being criticized, and no
one else, within 10 days after receiving the response.


Addendums will be peer reviewed before publication. It should be noted that addendums must not challenge the major findings of the main paper.

\section{A shared responsibility}

Our fight against scientific misconduct is a shared responsibility (Aronson 2007; Cross 2007; Titus et al. 2008; Rathod 2010). While JoTT requests the authors to follow the norms of scientific conduct faithfully and honestly, JoTT also assures the authors that the reviewing and editing process will be fair. JoTT requests the reviewers, subject editors as well as the readers to be vigilant against any form of scientific misconduct. JoTT also assures that none of the decisions will be taken hastily and all accusations will be evaluated objectively before taking any disciplinary actions.

\section{REFERENCES}

Alberts, B., B. Hanson \& K.L. Kelner (2008). Reviewing peer review. Science 321: 15.

Amstrong, J.D. II (1993). Plagiarism: what is it, whom does it offend, and how does one deal with it? American Journal of Roentgenology 161: 479-484.

Anonymous (2011). The European Code of Conduct for Research Integrity. Published by European Science Foundation and ALLEA (All European Academies), 24pp. <http://www.esf. org/activities/mo-fora/research-integrity.htm Accessed on 16 August 2012>

Aronson, J.K. (2007). Plagiarism-please don't copy. British Journal of Clinical Pharmacology 64(4): 403-405.

Benos, D.J., E. Bashari, J.M. Chaves, A. Gaggar, N. Kapoor, M. LaFrance, R. Mans, D. Mayhew, S. McGowan, A. Polter, Y. Qadri, S. Sarfare, K. Schultz, R. Splittgerber, J. Stephenson, C. Tower, R.G. Walton \& A. Zotov (2007). The ups and downs of peer review. Advances in Physiology Education 31: 145-152.

Berkenkotter, C. (1995). The power and the perils of peer review. Rhetoric Review 13(2): 245-248.

Cross, M. (2007). Policing plagiarism. British Madical Journal 335: 963-964.

Editorial (2011). Combating scientific misconduct. Nature Cell Biology 13(1): 1.

Errami, M. \& H. Garner (2008). A tale of two citations. Nature 451: 397-399.

Errami, M., J.M. Hicks, W. Fisher, D. Trusty, J.D. Wren, T.C. Long \& H.R. Garner (2008). Deja vu-a study of duplicate citations in Medline. Bioinformatics 24: 243-249.

Fanelli, D. (2009). How many scientists fabricate and falsify research? A systematic review and meta-analysis of survey data. PLoS ONE 4: e5738.

Handa, S. (2008). Plagiarism and publication ethics: Dos and don'ts. Indian Journal of Dermatology, Venereology and Leprology 74: 301-303

Kassirer, J.P. \& E.W. Campion (1994). Peer review: crude and understudied, but indispensable. JAMA: The Journal of the American Medical Association 272: 96-97.

Laband, D.N. \& M.J. Piette (1994). A citation analysis of the impact of blinded peer review. JAMA: The Journal of the American Medical Association 272: 147-149.

Long, T.C., M. Errami, A.C. George, Z. Sun \& H.R. Garner (2009). Responding to possible plagiarism. Science 323: 1293-1294.

Martinson, B.C., M.S. Anderson \& R. de Vries (2005). Scientists behaving badly. Nature 435: 737-738.

McNutt, R.A, A.T. Evans, R.H. Fletcher \& S.W. Fletcher (1990). The effects of blinding on the quality of peer review. JAMA: The Journal of the American Medical Association 263: 1371-1376.

Montgomerie, B. \& T. Birkhead (2005). A beginner's guide to scientific misconduct. International Society for Behavioral Ecology 17(1): 16-24.

Mukunda, N. \& A. Joshi (2008). Note on plagiarism. Journal of Genetics 87: 99.

Rathod, S.D. (2010). Combating plagiarism: a shared responsibility. Indian Journal of Medical Ethics 7: 173-175.

Redman, B.K. \& J.F. Merz (2008). Scientific misconduct: do the punishments fit the crime? Science 321: 775.

Relman, A.S. (1990). Peer review in scientific journals - what good is it? The Western Journal of Medicine 153: 520-522.

Resnik, D.B. (2003). From Baltimore to Bell Labs: reflections on two decades of debate about scientific misconduct. Accountability in Research: Policies and Quality Assurance 10(2): 123-135.

Resnik, D.B. \& C.N. Stewart Jr. (2012). Misconduct versus honest error and scientific disagreement. Accountability in Research: Policies and Quality Assurance 19(1): 56-63.

Resnik, D.B., S. Peddada \& W. Brunson Jr. (2009). Research misconduct policies of scientific journals. Accountability in Research: Policies and Quality Assurance 16(5): 254-267.

Smith, R. (2006). Peer review: a flawed process at the heart of science and journals. Journal of the Royal Society of Medicine 99: 178-182.

Spier, R. (2002). The history of the peer-review process. Trends in Biotechnology 20(8): 357-358.

Titus, S.L., J.A. Wells \& L.J. Rhoades (2008). Repairing research integrity. Nature 453: 980-982.

Triggle, C.R. \& D. J. Triggle (2007). What is the future of peer review? Why is there fraud in science? Is plagiarism out of control? Why do scientists do bad things? Is it all a case of: "all that is necessary for the triumph of evil is that good men do nothing"? Vascular Health and Risk Management 3(1): 39-53.

van Rooyen, S., F. Godlee, S. Evans, R. Smith \& N. Black (1998). Effect of blinding and unmasking on the quality of peer review: a randomized trial. JAMA: The Journal of the American Medical Association 280: 234-237. 